\title{
NONLINEAR CONTRACTIONS IN PARTIALLY ORDERED QUASI $b$-METRIC SPACES
}

\author{
Masood Hussain Shah and Nawab Hussain
}

\begin{abstract}
Using the concept of a $g$-monotone mapping we prove some common fixed point theorems for $g$-non-decreasing mappings which satisfy some generalized nonlinear contractions in partially ordered complete quasi $b$-metric spaces. The new theorems are generalizations of very recent fixed point theorems due to L. Ciric, N. Cakic, M. Rojovic, and J. S. Ume, [Monotone generalized nonlinear contractions in partailly ordered metric spaces, Fixed Point Theory Appl. (2008), article, ID-131294] and R. P. Agarwal, M. A. El-Gebeily, and D. O'Regan [Generalized contractions in partially ordered metric spaces, Appl. Anal. 87 (2008), 1-8].
\end{abstract}

\section{Introduction}

The extension of Banach fixed point theorem for contractive mappings has been done in many directions (cf. [1]-[15]). Recently, Agarwal et al. [1] and Ciric et al. [5], have come up with some new fixed and common fixed point theorems of mappings satisfying certain generalized nonlinear contractions in partially ordered metric spaces. The main idea in [1], [10] and [14] involve combining the ideas of iterative technique in the contraction mapping principle with those in the monotone technique.

The aim of this paper is to extend the results of [1] and [5] to the setting of partially ordered complete quasi $b$-metric spaces, by using some modified technique of [5]. Based on the concept of a $g$-monotone mapping we generalize some fixed point and common fixed point theorems for $g$-non-decreasing mappings satisfying some generalized nonlinear contractions in partially ordered complete quasi $b$-metric spaces.

Let $(X, \leq)$ be a partially ordered set. A mapping $F: X \rightarrow X$ is said to be non-decreasing if $x \leq y$ implies that $F(x) \leq F(y)$ for all $x, y \in X$. For completeness sake, the main results of [1] and [5] are described below.

Received July 29, 2010.

2010 Mathematics Subject Classification. Primary 54H25; Secondary 47H10.

Key words and phrases. $g$-monotone mapping, $g$-non-decreasing mapping, coincidence, fixed point, common fixed point, complete quasi $b$-metric space. 
Theorem 1.1 ([1, Theorem 2.2]). Let $(X, \leq)$ be a partially ordered set and suppose there is a metric $d$ on $X$ such that $(X, d)$ is a complete metric space. Assume there is a non-decreasing function $\psi:[0,+\infty) \rightarrow[0,+\infty)$ with

$$
\lim _{n \rightarrow \infty} \psi^{n}(t)=0
$$

for each $t>0$ and also suppose $F$ is a non-decreasing mapping with

$$
\begin{aligned}
& d(F(x), F(y)) \leq \psi(\max \{d(x, y), d(x, F(x)), d(y, F(y)), \\
& \left.\frac{1}{2}[d(x, F(y))+d(y, F(x)]\}\right)
\end{aligned}
$$

for all $x \geq y$. Also suppose either

(a) $F$ is continuous or

(b) if $\left\{x_{n}\right\} \subset X$ is a non-decreasing sequence with $x_{n} \rightarrow x$ in $X$, then $x_{n} \leq x$ for all $n$ hold.

If there exists an $x_{0} \in X$ with $x_{0} \leq F\left(x_{0}\right)$, then $F$ has a fixed point.

Agarwal, El-Gebeily and O'Regan [1] remove the condition that $\psi$ is nondecreasing in Theorem 1.1 and so they came up with the following fixed point theorem.

Theorem 1.2 ([1, Theorem 2.3]). Let $(X, \leq)$ be a partially ordered set and suppose there is a metric $d$ on $X$ such that $(X, d)$ is a complete metric space. Assume there is a continuous function $\psi:[0,+\infty) \rightarrow[0,+\infty)$ with $\psi(t)<t$ for each $t>0$ and also suppose $F$ is a non-decreasing mapping with

(2) $d(F(x), F(y)) \leq \psi(\max \{d(x, y), d(x, F(x)), d(y, F(y))\})$ for all $x \geq y$.

Also suppose either (a) or (b) hold. If there exists an $x_{0} \in X$ with $x_{0} \leq F\left(x_{0}\right)$, then $F$ has a fixed point.

The problem to extend Theorem 1.2 to mappings which satisfy (1) was addressed by Ciric et al. in the following theorem.

Theorem 1.3 ([5, Theorem 2.1]). Let $(X, \leq)$ be a partially ordered set and suppose there is a metric $d$ on $X$ such that $(X, d)$ is a complete metric space. Assume there is a continuous function $\varphi:[0,+\infty) \rightarrow[0,+\infty)$ with $\varphi(t)<t$ for each $t>0$ and also suppose $F, g: X \rightarrow X$ are such that $F(X) \subseteq g(X), F$ is a g-non-decreasing mapping and

(3)

$$
\begin{gathered}
d(F(x), F(y)) \leq \max \{\varphi(d(g(x), g(y))), \varphi(d(g(x), F(x))), \varphi(d(g(y), F(y))), \\
\left.\varphi\left(\frac{d(g(x), F(y))+d(g(y), F(x))}{2}\right)\right\}
\end{gathered}
$$

for all $x, y \in X$ for which $g(x) \geq g(y)$. Also suppose if $\left\{g\left(x_{n}\right)\right\} \subset X$ is a non-decreasing sequence with $g\left(x_{n}\right) \rightarrow g(z)$ in $g(X)$, then $g\left(x_{n}\right) \leq g(z)$ and 
$g(z) \leq g(g(z))$ for all $n$ hold. Also suppose $g(X)$ is closed. If there exists an $x_{0} \in X$ with $g\left(x_{0}\right) \leq F\left(x_{0}\right)$, then $F$ and $g$ have a coincidence. Further, if $F, g$ commute at their coincidence points, then $F$ and $g$ have a common fixed point.

In this paper we mainly extend Theorem 1.3, to the setting of a partially ordered complete quasi $b$-metric space, by modifying $\varphi$ and hence using a somewhat different technique.

\section{Main results}

The concept of $b$-metric space was introduced by Czerwik in [6]. Since then several papers deal with fixed point theory for single valued and multivalued operators in $b$-metric spaces (see $[2,6,15]$ and references therein).

Definition 2.1. Let $X$ be a non-empty set. A real-valued function $d: X \times X \rightarrow$ $\mathbb{R}^{+}$is said to be a quasi $b$-metric on $X$ with the constant $s \geq 1$ if the following conditions are satisfied:

$\left(M_{1}\right) d(x, y) \geq 0$ for all $x, y \in X$,

$\left(M_{2}\right) d(x, y)=0$ if and only if $x=y$,

$\left(M_{3}\right) d(x, z) \leq s(d(x, y)+d(y, z))$ for all $x, y, z \in X$.

The pair $(X, d)$ is called a quasi $b$-metric space. Observe that if $s=1$, then the ordinary triangle inequality is satisfied, however it does not hold true when $s>1$. Thus the class of quasi $b$-metric spaces is effectively larger than that of the ordinary quasi-metric spaces. That is, every quasi-metric space is a quasi $b$-metric space but the converse need not be true. The following example explains the above mentioned situation.

Example 2.2. Let $X=C([0,1], \mathbb{R})$ with the usual partial order. Define $d$ : $X \times X \rightarrow \mathbb{R}^{+}$by

$$
d(f, g)=\left\{\begin{array}{l}
\int_{0}^{1}[g(t)-f(t)]^{3} d t, \text { if } f \leq g, \\
\int_{0}^{1}[f(t)-g(t)]^{3} d t, \text { if } f \geq g .
\end{array}\right.
$$

Note that $d(f, g) \geq 0$ for all $f, g \in X$, and $d(f, g)=0$ if and only if $f=g$. Also $d(f, g)=d(g, f)$ if and only if $f=g$ so that $d$ is not symmetric.

Case $(a)$ Let $f(t)=2 t, g(t)=5 t$ and $h(t)=6 t$ for $t \in[0,1]$. Then

$$
\begin{aligned}
& d(f, h)=16, \\
& d(f, g)=\frac{27}{4}, \\
& d(g, h)=\frac{1}{4} .
\end{aligned}
$$

That is,

$$
d(f, h)>d(f, g)+d(g, h)
$$

so that the usual triangle inequality is not satisfied. Suppose that there exists $s>1$ such that

$$
d(f, h) \leq s[d(f, g)+d(g, h)]
$$

then putting the values and simplifying we get, $16 \leq 7 s$ or $s \geq \frac{16}{7}$. 
Thus for every $f, g, h \in X$, whenever the usual quasi-metric triangle inequality fails to hold, we can find an $s>1$ such that the triangle inequality of the quasi $b$-metric is satisfied.

Case $(b)$ Let $f(t)=-2 t, g(t)=-5 t$ and $h(t)=-6 t$ for $t \in[0,1]$. Then following the lines similar to Case (a) we conclude that the usual quasi-metric triangle inequality fails to hold and for every $f, g, h \in X$ we can find an $s>1$ such that the triangle inequality of the quasi $b$-metric is satisfied.

From the above discussion it follows that $(X, d)$ is a quasi $b$-metric space which is not an ordinary quasi-metric space.

Following example explains that the class of quasi $b$-metric spaces contains the class of the usual quasi-metric spaces.

Example 2.3. Let $X=l_{p}$, where $1 \leq p<\infty$, be defined by

$$
l_{p}=\left\{\left(x_{n}\right)_{n \geq 1} \subseteq \mathbb{R}: \sum_{n=1}^{\infty}\left|x_{n}\right|^{p}<\infty\right\} \text {. }
$$

Define $d: X \times X \rightarrow \mathbb{R}^{+}$by

$$
d(x, y)= \begin{cases}0 & \text { if } x \leq y \\ \left(\sum_{n=1}^{\infty}\left|x_{n}\right|^{p}\right)^{\frac{1}{p}} & \text { if } x \geq y\end{cases}
$$

Then $d$ satisfies all the conditions of a quasi $b$-metric with the constant $s=$ $p \geq 1$. Indeed, if $p=1$ the triangle inequality trivially holds; so let $p>1$ and $x=\left(x_{n}\right)_{n \geq 1} ; y=\left(y_{n}\right)_{n \geq 1} ; z=\left(z_{n}\right)_{n \geq 1}$ be sequences in $X$ with $x \neq y \neq z$. Then

$$
d(x, z)=\left(\sum_{n=1}^{\infty}\left|x_{n}\right|^{p}\right)^{\frac{1}{p}}=d(x, y) ; \quad d(y, z)=\left(\sum_{n=1}^{\infty}\left|y_{n}\right|^{p}\right)^{\frac{1}{p}}
$$

Since

$$
\left|x_{n}\right|^{p} \leq p\left|x_{n}\right|^{p}=p\left|x_{n}\right|\left|x_{n}\right|^{p-1} \leq p\left(\left|x_{n}\right|+\left|y_{n}\right|\right)\left|x_{n}\right|^{p-1} \text { for } n \in \mathbb{N},
$$

we have

$$
\begin{aligned}
\sum_{n=1}^{\infty}\left|x_{n}\right|^{p} & \leq p\left(\sum_{n=1}^{\infty}\left|x_{n}\right|\left|x_{n}\right|^{p-1}+\sum_{n=1}^{\infty}\left|y_{n}\right|\left|x_{n}\right|^{p-1}\right) \\
& \leq p\left\{\left(\sum_{n=1}^{\infty}\left|x_{n}\right|^{p}\right)^{\frac{1}{p}}+\left(\sum_{n=1}^{\infty}\left|y_{n}\right|^{p}\right)^{\frac{1}{p}}\right\}\left(\sum_{n=1}^{\infty}\left|x_{n}\right|^{q(p-1)}\right)^{\frac{1}{q}}
\end{aligned}
$$

simplifying we get

$$
\left(\sum_{n=1}^{\infty}\left|x_{n}\right|^{p)}\right)^{\frac{1}{p}} \leq p\left\{\left(\sum_{n=1}^{\infty}\left|x_{n}\right|^{p}\right)^{\frac{1}{p}}+\left(\sum_{n=1}^{\infty}\left|y_{n}\right|^{p}\right)^{\frac{1}{p}}\right\} .
$$


Thus

$$
d(x, y) \leq p(d(x, y)+d(y, z))
$$

and $d$ is a quasi $b$-metric on $X$.

Definition 2.4. Suppose $(X, \leq)$ is a partially ordered set and $F, g: X \rightarrow X$ are mappings of $X$ into itself. We say $F$ is $g$-non-decreasing if for $x, y \in X$,

$$
g(x) \leq g(y) \text { implies } F(x) \leq F(y) .
$$

The main theoretical result of this paper is the following theorem.

Theorem 2.5. Let $(X, \leq, d)$ be a partially ordered complete quasi b-metric space with the constant $s \geq 1$. Assume that the function $\varphi:[0,+\infty) \rightarrow[0,+\infty)$ is such that $\varphi(t)<\frac{t}{2 s}$ for each $t>0$ and $F, g: X \rightarrow X$ are such that $F(X) \subseteq$ $g(X), F$ is a $g$-non-decreasing mapping and

$$
\begin{aligned}
d(F(x), F(y)) \leq \max \{ & \varphi(d(g(x), g(y))), \varphi(d(g(x), F(x))), \\
\varphi\left(\frac{1}{2}[d(g(y), F(y))+d(g(x), F(x))]\right), & \left.\left(\frac{1}{2 s}[d(g(x), F(y))+d(g(y), F(x))]\right)\right\}
\end{aligned}
$$

for all $x, y \in X$ for which $g(x) \geq g(y)$. Further, suppose that $g(X)$ is closed and

$$
\text { if }\left\{g\left(x_{n}\right)\right\} \subset X \text { is a non-decreasing sequence with } g\left(x_{n}\right) \rightarrow g(z) \text { in } g(X) \text {, }
$$

then $g\left(x_{n}\right) \leq g(z)$ and $g(z) \leq g(g(z))$ for all $n$ hold.

If there exists an $x_{0} \in X$ with $g\left(x_{0}\right) \leq F\left(x_{0}\right)$, then $F$ and $g$ have a coincidence, and if $F, g$ commute at their coincidence points, then $F$ and $g$ have a common fixed point.

Proof. Choose $x_{0} \in X$ such that $g\left(x_{0}\right) \leq F\left(x_{0}\right)$. Since $F(X) \subseteq g(X)$, there exists $x_{1} \in X$ such that $g\left(x_{1}\right)=F\left(x_{0}\right)$. Again $F(X) \subseteq g(X)$ implies that there exists $x_{2} \in X$ such that $g\left(x_{2}\right)=F\left(x_{1}\right)$. Continuing this process we can obtain a sequence $\left\{x_{n}\right\}$ in $X$ such that

$$
g\left(x_{n+1}\right)=F\left(x_{n}\right) \text { for all } n \geq 0 .
$$

Since $g\left(x_{0}\right) \leq g\left(x_{1}\right)$ from $(4)$

$$
F\left(x_{0}\right) \leq F\left(x_{1}\right)
$$

Thus, by (7), $g\left(x_{1}\right) \leq g\left(x_{2}\right)$ and (4),

$$
F\left(x_{1}\right) \leq F\left(x_{2}\right),
$$

that is, $g\left(x_{2}\right) \leq g\left(x_{3}\right)$. Proceeding in this way, we get

(8) $\quad F\left(x_{0}\right) \leq F\left(x_{1}\right) \leq F\left(x_{2}\right) \leq F\left(x_{3}\right) \leq \cdots \leq F\left(x_{n}\right) \leq F\left(x_{n+1}\right) \leq \cdots$. 
Let $\delta_{n}=d\left(F\left(x_{n}\right), F\left(x_{n+1}\right)\right)$. We shall prove that

$$
\delta_{n}<\frac{\delta_{n-1}}{2 s} \text { for all } n \geq 1 \text {. }
$$

Since $g\left(x_{n}\right) \leq g\left(x_{n+1}\right)$ for all $n \geq 0$, putting $x=x_{n}$ and $y=x_{n+1}$ into (5) we get

$$
\begin{aligned}
& d\left(F\left(x_{n}\right), F\left(x_{n+1}\right)\right) \max \left\{\varphi\left(d\left(g\left(x_{n}\right), g\left(x_{n+1}\right)\right)\right), \varphi\left(d\left(g\left(x_{n}\right), F\left(x_{n}\right)\right)\right),\right. \\
& \varphi\left(\frac{1}{2}\left[d\left(g\left(x_{n+1}\right), F\left(x_{n+1}\right)\right)+d\left(g\left(x_{n}\right), F\left(x_{n}\right)\right)\right]\right), \\
&\left.\varphi\left(\frac{1}{2 s}\left[d\left(g\left(x_{n}\right), F\left(x_{n+1}\right)\right)+d\left(g\left(x_{n+1}\right), F\left(x_{n}\right)\right)\right]\right)\right\} .
\end{aligned}
$$

And by (7),

$$
\begin{aligned}
& d\left(F\left(x_{n}\right), F\left(x_{n+1}\right)\right) \\
& \leq \max \left\{\varphi\left(d\left(F\left(x_{n-1}\right), F\left(x_{n}\right)\right)\right), \varphi\left(d\left(F\left(x_{n-1}\right), F\left(x_{n}\right)\right)\right),\right. \\
& \varphi\left(\frac{1}{2}\left[d\left(F\left(x_{n}\right), F\left(x_{n+1}\right)\right)+d\left(F\left(x_{n-1}\right), F\left(x_{n}\right)\right)\right]\right), \\
&\left.\varphi\left(\frac{1}{2 s} d\left(F\left(x_{n-1}\right), F\left(x_{n+1}\right)\right)\right)\right\} .
\end{aligned}
$$

Or

$$
\begin{aligned}
& d\left(F\left(x_{n}\right), F\left(x_{n+1}\right)\right) \\
\leq & \max \left\{\varphi\left(d\left(F\left(x_{n-1}\right), F\left(x_{n}\right)\right)\right),\right. \\
& \varphi\left(\frac{1}{2}\left[d\left(F\left(x_{n}\right), F\left(x_{n+1}\right)\right)+d\left(F\left(x_{n-1}\right), F\left(x_{n}\right)\right)\right]\right), \\
& \left.\varphi\left(\frac{1}{2 s} d\left(F\left(x_{n-1}\right), F\left(x_{n+1}\right)\right)\right)\right\} .
\end{aligned}
$$

If $d\left(F\left(x_{n}\right), F\left(x_{n+1}\right)\right) \leq \varphi\left(d\left(F\left(x_{n-1}\right), F\left(x_{n}\right)\right)\right)$, then (9) holds, as $\varphi(t)<\frac{t}{2 s}$ for $t>0$. If

$$
d\left(F\left(x_{n}\right), F\left(x_{n+1}\right)\right) \leq \varphi\left(\frac{1}{2}\left[d\left(F\left(x_{n}\right), F\left(x_{n+1}\right)\right)+d\left(F\left(x_{n-1}\right), F\left(x_{n}\right)\right)\right]\right),
$$

then we have

$$
\begin{aligned}
\left.d\left(F\left(x_{n}\right), F\left(x_{n+1}\right)\right)\right) & \leq \varphi\left(\frac{1}{2}\left[d\left(F\left(x_{n}\right), F\left(x_{n+1}\right)\right)+d\left(F\left(x_{n-1}\right), F\left(x_{n}\right)\right)\right]\right) \\
& <\frac{\frac{1}{2}\left[d\left(F\left(x_{n}\right), F\left(x_{n+1}\right)\right)+d\left(F\left(x_{n-1}\right), F\left(x_{n}\right)\right)\right]}{2 s} \\
& =\frac{1}{4 s}\left[d\left(F\left(x_{n}\right), F\left(x_{n+1}\right)\right)+d\left(F\left(x_{n-1}\right), F\left(x_{n}\right)\right)\right]
\end{aligned}
$$


or

$$
\left.d\left(F\left(x_{n}\right), F\left(x_{n+1}\right)\right)\right)<\frac{1}{4 s-1} d\left(F\left(x_{n-1}\right), F\left(x_{n}\right) \leq \frac{1}{2 s} d\left(F\left(x_{n-1}\right), F\left(x_{n}\right)\right) .\right.
$$

Thus

$$
\delta_{n}=d\left(F\left(x_{n}\right), F\left(x_{n+1}\right)\right)<\frac{1}{2 s} d\left(F\left(x_{n-1}\right), F\left(x_{n}\right)=\frac{\delta_{n-1}}{2 s} .\right.
$$

Lastly, if $d\left(F\left(x_{n}\right), F\left(x_{n+1}\right)\right) \leq \varphi\left(d\left(F\left(x_{n-1}\right), F\left(x_{n+1}\right)\right) / 2 s\right)$, then we have

$$
\begin{aligned}
d\left(F\left(x_{n}\right), F\left(x_{n+1}\right)\right) & \leq \varphi\left(\frac{1}{2 s} d\left(F\left(x_{n-1}\right), F\left(x_{n+1}\right)\right)\right) \\
& <\frac{1}{4 s^{2}} d\left(F\left(x_{n-1}\right), F\left(x_{n+1}\right)\right) \\
& \leq \frac{1}{4 s^{2}}\left(s\left[d\left(F\left(x_{n-1}\right), F\left(x_{n}\right)\right)+d\left(F\left(x_{n}\right), F\left(x_{n+1}\right)\right)\right]\right) \\
& =\frac{1}{4 s}\left[d\left(F\left(x_{n-1}\right), F\left(x_{n}\right)\right)+d\left(F\left(x_{n}\right), F\left(x_{n+1}\right)\right)\right]
\end{aligned}
$$

simplifying we get

$$
d\left(F\left(x_{n}\right), F\left(x_{n+1}\right)\right)<\frac{1}{4 s-1} d\left(F\left(x_{n-1}\right), F\left(x_{n}\right)\right) \leq \frac{\delta_{n-1}}{2 s} .
$$

Therefore, we have proved that (9) holds. It follows from (9) that for every $s \geq 1$

$$
0 \leq \delta_{n}<\frac{\delta_{n-1}}{(2 s)}<\frac{\delta_{n-2}}{(2 s)^{2}}<\frac{\delta_{n-3}}{(2 s)^{3}}<\cdots<\frac{\delta_{0}}{(2 s)^{n}}
$$

and so

$$
\lim _{n \rightarrow \infty} \delta_{n}=0
$$

Now we prove that $\left\{F\left(x_{n}\right)\right\}$ is a Cauchy sequence. Let $m>n$. Then we have

$$
\begin{aligned}
d\left(F\left(x_{n}\right), F\left(x_{m}\right)\right) \leq & s d\left(F\left(x_{n}\right), F\left(x_{n+1}\right)\right)+s^{2} d\left(F\left(x_{n+1}\right), F\left(x_{n+2}\right)\right) \\
& +s^{3} d\left(F\left(x_{n+2}\right), F\left(x_{n+3}\right)\right)+\cdots+s^{m} d\left(F\left(x_{m-1}\right), F\left(x_{m}\right)\right) \\
= & s \delta_{n}+s^{2} \delta_{n+1}+s^{3} \delta_{n+2}+\cdots+s^{m} \delta_{m-1} \\
\leq & s \delta_{n}+\left(\frac{s \delta_{n}}{2}+\frac{s \delta_{n}}{2^{2}}+\cdots+\frac{s \delta_{n}}{2^{m-n-1}}\right) \\
\leq & s \delta_{n}\left(1+\frac{1}{2}+\frac{1}{2^{2}}+\frac{1}{2^{3}}+\cdots\right)=2 s \delta_{n} \rightarrow 0 \text { as } n \rightarrow \infty .
\end{aligned}
$$

Therefore, $\left\{F\left(x_{n}\right)\right\}$ is a Cauchy sequence. Since $\left\{F\left(x_{n}\right)\right\}=\left\{g\left(x_{n+1}\right)\right\} \subseteq g(X)$ and $g(X)$ is closed, there exists $z \in X$ such that

$$
\lim _{n \rightarrow \infty} g\left(x_{n}\right)=g(z)\left(=\lim _{n \rightarrow \infty} F\left(x_{n-1}\right)\right) .
$$


Now we show that $z$ is a coincidence of $F$ and $g$. Since from (6) and (11) we have $g\left(x_{n}\right) \leq g(z)$ for all $n$, then by the triangle inequality and (5) we get

$$
\begin{aligned}
& d(g(z), F(z)) \\
\leq s\left[d\left(g(z), F\left(x_{n}\right)\right)+d(\right. & \left.\left.F\left(x_{n}\right), F(z)\right)\right] \\
\leq s d\left(g(z), F\left(x_{n}\right)\right)+s[ & \max \left\{\varphi\left(d\left(g\left(x_{n}\right), g(z)\right)\right), \varphi\left(d\left(g\left(x_{n}\right), F\left(x_{n}\right)\right)\right),\right. \\
& \varphi\left(\frac{1}{2} d(g(z), F(z))+d\left(g\left(x_{n}\right), F\left(x_{n}\right)\right)\right), \\
& \left.\left.\varphi\left(\frac{d\left(g\left(x_{n}\right), F(z)\right)+d\left(g(z), F\left(x_{n}\right)\right)}{2 s}\right)\right\}\right] \\
<s d\left(g(z), F\left(x_{n}\right)\right)+s[ & \max \left\{\frac{1}{2 s} d\left(g\left(x_{n}\right), g(z)\right), \frac{1}{2 s}\left(d\left(g\left(x_{n}\right), F\left(x_{n}\right)\right),\right.\right. \\
& \frac{1}{4 s}\left(d(g(z), F(z))+d\left(g\left(x_{n}\right), F\left(x_{n}\right)\right)\right), \\
& \left.\left.\frac{d\left(g\left(x_{n}\right), F(z)\right)+d\left(g(z), F\left(x_{n}\right)\right)}{4 s^{2}}\right\}\right] .
\end{aligned}
$$

Applying limit on both sides as $n \rightarrow \infty$ and simplifying, we get

$$
d(g(z), F(z)) \leq \max \left\{\frac{1}{2} d(g(z), F(z)), \frac{1}{4 s} d(g(z), F(z))\right\}=\frac{1}{2} d(g(z), F(z)) .
$$

Hence $d(g(z), F(z))=0$, and so $F(z)=g(z)$. Thus $F$ and $g$ have a coincidence $z$.

Suppose that $F g(x)=g F(x)$ for all $x \in X$. Set $w=g(z)=F(z)$. Then

$$
F(w)=F(g(z))=g(F(z))=g(w) .
$$

Since $\left\{g\left(x_{n}\right)\right\}$ is a non-decreasing with $\lim _{n \rightarrow \infty} g\left(x_{n}\right)=g(z)$, from (6) we have $g(z) \leq g(g(z))=g(w)$ and as $g(z)=F(z)$ and $g(w)=F(w)$, from (5) we get

$$
\begin{aligned}
& d(w, F(w))= d(F(z), F(w)) \\
& \leq \max \{\varphi(d(g(z), g(w))), \varphi(d(g(z), F(z))), \\
&\left(\frac{1}{2} d(g(w), F(w))+d(g(z), F(z))\right), \\
&\left.\varphi\left(\frac{d(g(z), F(w))+d(g(w), F(z))}{2 s}\right)\right\} \\
&<\max \left\{\frac{1}{2 s} d(g(z), g(w)), \frac{d(g(z), F(w))+d(g(w), F(z))}{4 s^{2}}\right\} .
\end{aligned}
$$

If

$$
d(F(z), F(w))<\frac{1}{2 s} d(g(z), g(w))
$$


then clearly $d(F(z), F(w))=0$. If

$$
d(F(z), F(w)) \leq \frac{d(g(z), F(w))+d(g(w), F(z))}{4 s^{2}},
$$

then this gives us

$$
d(F(z), F(w))<\frac{d(F(w), F(z))}{4 s^{2}-1} .
$$

Interchanging $w$ and $z$ in the equation (12) and simplifying we get

$$
d(F(w), F(z))<\frac{d(F(z), F(w))}{4 s^{2}-1} .
$$

Thus from equations (12) and (13), we get

$$
d(F(z), F(w))<\frac{d(F(w), F(z))}{4 s^{2}-1}<\frac{d(F(z), F(w))}{\left(4 s^{2}-1\right)^{2}} .
$$

This implies that $d(F(z), F(w))=0$. Thus we get $d(w, F(w))=0$, implying that

$$
F(w)=g(w)=w
$$

and hence $F, g$ have a common fixed point.

Remark 2.6. Theorem 2.5 also holds true if $F$ is $g$-non-decreasing be replaced with $F$ is $g$-non-increasing and $g\left(x_{0}\right) \leq F\left(x_{0}\right)$ be replaced with $F\left(x_{0}\right) \geq g\left(x_{0}\right)$.

Example 2.7. Let $X=[-1,1]$ with the usual partial order. Define $d: X \times$ $X \rightarrow \mathbb{R}^{+}$by

$$
d(x, y)= \begin{cases}0 & \text { if and only if } x=y \\ \left|x-\frac{y}{2}\right|^{2} & \text { otherwise. }\end{cases}
$$

Note that $d(x, y) \geq 0$ for all $x, y \in X$, and $d(x, y)=0$ if and only if $x=y$. Also $d(x, y)=d(y, x)$ if and only if $x=y$ so that $d$ is not symmetric. Let $x=1, y=0$ and $z=-1$. Then

$$
\begin{aligned}
& d(x, z)=2.25 \\
& d(x, y)=1, \\
& d(y, z)=\frac{1}{4},
\end{aligned}
$$

so that the usual triangle inequality is not satisfied. However if $p \in(0,1]$, then we have

$$
d(x, z) \leq 2^{\frac{1}{p}}(d(x, y)+d(y, z)) .
$$

Since $s=2^{\frac{1}{p}} \geq 2$ for $p \in(0,1]$, so $d$ is a quasi $b$-metric on $X$ which is not a usual quasi-metric on $X$. Thus $(X, \leq, d)$ is a partially ordered complete quasi $b$-metric space with the constant $s \geq 2$. Define $F, g: X \rightarrow X$ by $F(x)=\frac{x}{6}$ and $g(x)=x$. Let $\varphi:[0,+\infty) \rightarrow[0,+\infty)$ be defined by $\varphi(t)=\frac{t}{3}$. Observe that

$$
\text { for } x, y \in X, \quad g(x) \leq g(y) \Longrightarrow F(x) \leq F(y)
$$


and hence $F$ is $g$-nondecreasing. Also for $g(x) \geq g(y)$

$$
d(F(x), F(y))=\left|F(x)-\frac{F(y)}{2}\right|^{2}=\frac{1}{36}\left|x-\frac{y}{2}\right|^{2} \leq \frac{1}{16}
$$

when $x=1$ and $y=-1$. On the other hand we have

$$
\begin{aligned}
\varphi(d(g(x), g(y))) & \leq \frac{3}{4}, \\
\varphi(d(g(x), F(x))) & \leq \frac{1}{16}\left(\frac{121}{27}\right), \\
\varphi\left(\frac{1}{2}[d(g(y), F(y))+d(g(x), F(x))]\right) & \leq \frac{1}{16}\left(\frac{121}{27}\right), \\
\varphi\left(\frac{1}{2 s}[d(g(x), F(y))+d(g(y), F(x))]\right) & \leq \frac{1}{16 s}\left(\frac{169}{27}\right) .
\end{aligned}
$$

Thus

$$
d(F(x), F(y)) \leq \max \left\{\begin{array}{c}
\varphi(d(g(x), g(y))), \varphi(d(g(x), F(x))), \\
\varphi\left(\frac{1}{2}[d(g(y), F(y))+d(g(x), F(x))]\right), \\
\varphi\left(\frac{1}{2 s}[d(g(x), F(y))+d(g(y), F(x))]\right)
\end{array}\right\}
$$

and so $F$ satisfy the contraction condition. Also $g$ is continuous and nondecreasing and $x_{n} \rightarrow x$ implies that $g\left(x_{n}\right) \rightarrow g(x)$ so that by Theorem 2.5 $g\left(x_{n}\right) \leq g(x)$ for all $n \geq 1$ and $g(x) \leq g g(x)$. Note that $g(X)=[-1,1]$ and $F(X)=\left[-\frac{1}{6}, \frac{1}{6}\right] \subseteq g(X)$. Let $x_{0}=-\frac{1}{2}$; then since

$$
g\left(-\frac{1}{2}\right)=-\frac{1}{2}<-\frac{1}{12}=F\left(-\frac{1}{2}\right)
$$

by Theorem $2.5, F$ and $g$ have a coincidence. Since

$$
F g\left(-\frac{1}{2}\right)=-\frac{1}{12}=g F\left(-\frac{1}{2}\right)
$$

by Theorem 2.5, $F$ and $g$ have a common fixed point.

Corollary 2.8. Let $(X, \leq, d)$ be a partially ordered complete quasi b-metric space with the constant $s \geq 1$. Assume there is a function $\varphi:[0,+\infty) \rightarrow$ $[0,+\infty)$ with $\varphi(t)<\frac{t}{2 s}$ for each $t>0$ and also suppose $F: X \rightarrow X$ is a non-decreasing mapping and

$$
\begin{gathered}
d(F(x), F(y)) \leq \max \left\{\varphi(d(x, y)), \varphi(d(x, F(x))), \varphi\left(\frac{d(y, F(y)))+d(x, F(x))}{2}\right),\right. \\
\left.\varphi\left(\frac{d(x, F(y))+d(y, F(x))}{2 s}\right)\right\}
\end{gathered}
$$

for all $x, y \in X$ for which $x \leq y$. Also suppose either (i) if $\left\{x_{n}\right\} \subset X$ is a non-decreasing sequence with $x_{n} \rightarrow z$ in $X$, then $x_{n} \leq z$ for all $n$ hold or (ii) $F$ is continuous.

If there exists an $x_{0} \in X$ with $x_{0} \leq F\left(x_{0}\right)$, then $F$ has a fixed point. 
Proof. Suppose (i) holds, then the corollary follows by taking $g=I$ (the identity mapping on $X$ ) in Theorem 2.5. If (ii) holds, then from (11) with $g=I$ we get

$$
z=\lim _{n \rightarrow \infty} x_{n+1}=\lim _{n \rightarrow \infty} F\left(x_{n}\right)=F\left(\lim _{n \rightarrow \infty} x_{n}\right)=F(z)
$$

Corollary 2.9. Let $(X, \leq, d)$ be a partially ordered complete quasi b-metric space with the constant $s \geq 1$. Assume there is a function $\varphi:[0,+\infty) \rightarrow$ $[0,+\infty)$ with $\varphi(t)<\frac{t}{2 s}$ for each $t>0$ and $F: X \rightarrow X$ is a non-decreasing mapping such that

$$
\begin{aligned}
& d(F(x), F(y)) \\
\leq & \max \left\{\varphi(d(x, y)), \varphi(d(x, F(x))), \varphi\left(\frac{d(y, F(y))+d(x, F(x))}{2 s}\right)\right\}
\end{aligned}
$$

for all $x, y \in X$ for which $x \leq y$. Further, suppose either (i) if $\left\{x_{n}\right\} \subset X$ is a non-decreasing sequence with $x_{n} \rightarrow z$ in $X$, then $x_{n} \leq z$ for all $n$ hold or (ii) $F$ is continuous.

If there exists an $x_{0} \in X$ with $x_{0} \leq F\left(x_{0}\right)$, then $F$ has a fixed point.

Proof. Follows from Theorem 2.5 with $g=I$, where $I$ is the identity mapping on $X$.

Corollary 2.10. Let $(X, \leq, d)$ be a partially ordered complete quasi b-metric space with the constant $s \geq 1$. Suppose that $F: X \rightarrow X$ is a non-decreasing mapping such that

$$
\begin{aligned}
d(F(x), F(y)) \leq \frac{1}{3 s} \max \{ & d(x, y), d(x, F(x)), \frac{d(y, F(y))+d(x, F(x))}{2}, \\
& \left.\frac{d(x, F(y))+d(y, F(x))}{2 s}\right\}
\end{aligned}
$$

for all $x, y \in X$ for which $x \leq y$. Also suppose either (i) if $\left\{x_{n}\right\} \subset X$ is a non-decreasing sequence with $x_{n} \rightarrow z$ in $X$, then $x_{n} \leq z$ for all $n$ hold or (ii) $F$ is continuous.

If there exists an $x_{0} \in X$ with $x_{0} \leq F\left(x_{0}\right)$, then $F$ has a fixed point.

Proof. It follows from Theorem 2.5 with $\varphi(t)=\frac{t}{3 s}$ and $g=I$, where $I$ is the identity mapping on $X$.

\section{References}

[1] R. P. Agarwal, M. A. El-Gebeily, and D. O'Regan, Generalized contractions in partially ordered metric spaces, Appl. Anal. 87 (2008), no. 1, 109-116.

[2] V. Berinde, Generalized contractions in quasimetric spaces, Seminar on Fixed Point Theory, 3-9, Preprint, 93-3, "Babeş-Bolyai" Univ., Cluj-Napoca, 1993.

[3] D. W. Boyd and J. S. Wong, On nonlinear contractions, Proc. Amer. Math. Soc. 20 (1969), 458-464.

[4] L. Ćirić, Common fixed points of nonlinear contractions, Acta Math. Hungar. 80 (1998), no. 1-2, 31-38. 
[5] L. Ćirić, N. Cakic, M. Rojovic, and J. S. Ume, Monotone generalized nonlinear contractions in partially ordered metric spaces, Fixed Point Theory Appl. (2008), Art. ID 131294, 11 pp.

[6] S. Czerwik, Nonlinear set-valued contraction mappings in b-metric spaces, Atti Sem. Mat. Fis. Univ. Modena 46 (1998), no. 2, 263-276.

[7] Lj. Gajić and V. Rakočević, Quasicontraction nonself-mappings on convex metric spaces and common fixed point theorems, Fixed Point Theory Appl. 2005 (2005), no. 3, 365375 .

[8] N. Hussain, Common fixed points in best approximation for Banach operator pairs with Ćirić Type I-contractions, J. Math. Anal. Appl. 338 (2008), no. 2, 1351-1363.

[9] M. A. Khamsi and N. Hussain, KKM mappings in metric type spaces, Nonlinear Anal. 73 (2010), no. 9, 3123-3129.

[10] J. J. Nieto and R. Rodríguez-López, Contractive mapping theorems in partially ordered sets and applications to ordinary differential equations, Order 22 (2005), no. 3, 223-239.

[11] _ Existence and uniqueness of fixed point in partially ordered sets and applications to ordinary differential equations, Acta Math. Sin. (Engl. Ser.) 23 (2007), no. 12, 22052212.

[12] J. J. Nieto, R. L. Pouso, and R. Rodríguez-López, Fixed point theorems in ordered abstract spaces, Proc. Amer. Math. Soc. 135 (2007), no. 8, 2505-2517.

[13] S. Radenović and Z. Kadelburg, Quasi-contractions on symmetric and cone symmetric spaces, Banach J. Math. Anal. 5 (2011), no. 1, 38-50.

[14] A. C. M. Ran and M. C. B. Reurings, A fixed point theorem in partially ordered sets and some applications to matrix equations, Proc. Amer. Math. Soc. 132 (2004), no. 5, 1435-1443.

[15] S. L. Singh, S. Czerwik, K. Król, and A. Singh, Coincidences and fixed points of hybrid contractions, Tamsui Oxf. J. Math. Sci. 24 (2008), no. 4, 401-416.

Masood Hussain ShaH

Department of Mathematical Sciences

LUMS, DHA Lahore 54792, Pakistan

E-mail address: mshah@lums.edu.pk

Nawab Hussain

Department of Mathematics

King Abdulaziz University

P.O. Box 80203, Jeddah 21589, Saudi Arabia

E-mail address: nhusain@kau.edu.sa 